\section{Measles vaccination}

My initial response to the CMAJ editorial by Giddings ${ }^{1}$ was, "Really, are we really still hoping that advocacy is going to overcome vaccine hesitancy and resistance?"

Giddings ${ }^{1}$ properly identifies complacency and misinformation as important causes of reduced rates of pediatric immunization, but mistakenly encourages physicians to try to reason with emotion. Front-line primary care workers might like the notion that we can influence immunization resistance, but research tells us we will fail. ${ }^{2}$

The lay press portrays parents who are antivaccine as caring people who carefully consider their options. Unfortunately, this is wrong: those who do not vaccinate their children not only decide for their children, but for all children who come in contact with their children. It is not their right to do so.

The Canadian medical community should stop arguing, cajoling and pleading with those who refuse to have their children vaccinated, and instead, provide leadership in establishing an ethical process for mandatory vaccination of all children.

\section{Mark Dermer MD}

Family physician, Ottawa, Ont.

\section{References}

1. Giddings G. Measles vaccination: a shot of common sense. CMAJ 2014; 186:651.

2. Nyhan B. Reifler J, Richey S, et al. Effective messages in vaccine promotion: a randomized trial. Pediatrics 2014;33:e835-42.

CMAJ 2015. DOI:10.1503/cmaj.115-0000

\section{Ruptured thoracic aortic aneurysm and aortic dissection are entirely different entities}

Wells and Sun describe a 78-year-old man with a ruptured thoracic aortic aneurysm. ${ }^{1}$ Many of the teaching points made are incorrect.

The ruptured aneurysm described is caused by the same pathological process as the abdominal aortic aneurysm (atherosclerosis). The authors fail to assign this etiology and instead discuss aortic dissection, using the two terms interchangeably, as if they are one and the same.

Having incorrectly implied that their patient had aortic dissection, the authors go on to discuss aortic dissection, but fail to mention the universally applied Stanford Classification or the most common cause of dissection in a 78-year-old man, hypertension. Instead, they include Ehlers-Danlos syndrome on their list.

Much of the article describes lower blood pressure in the left arm compared to the right. The blood pressure in one arm can be decreased because of obstruction of inflow by the flap in some patients with dissection, usually type A. However, blood-pressure difference between arms is irrelevant in a patient with a ruptured aneurysm of the descending thoracic aorta. The patient almost certainly had an incidental atherosclerotic stenosis or occlusion of his left subclavian artery.

All mention of aortic dissection should have been deleted from the article, or mentioned only as part of a brief discussion of acute aortic syndrome. ${ }^{2}$ The authors ${ }^{1}$ should have stressed the message that chest pain in a patient known to have a large thoracic aneurysm (or with a chest radiograph showing a large aneurysm) should lead to a provisional diagnosis of aneurysm rupture, without waiting for hypotension or pleural effusion to develop. This is similar to abdominal pain in a patient known to have a large abdominal aortic aneurysm.

\section{Steven Millward MB ChB}

Radiologist, Peterborough Regional Health Centre, Peterborough, Ont.

\section{References}

1. Wells MM, Sun D. Acute pleural effusion from aortic aneurysm rupture. CMAJ 2014;186:451.

2. Vilacosta I, Roman JA. Acute aortic syndrome. Heart 2001;85;365-8.

CMAJ 2015. DOI:10.1503/cmaj.115-0004

\section{Letters to the editor}

Letters have been abbreviated for print. See www.cmaj.ca for full versions and competing interests. 